\title{
Circulating Protein Biomarkers to Differentiate Uterine Sarcomas from Leiomyomas
}

\author{
NATHALIE GLORIE ${ }^{1}$, THAÏS BAERT ${ }^{2,3}$, THIERRY VAN DEN BOSCH $^{1,4}$ and AN COOSEMANS ${ }^{1,2}$ \\ ${ }^{1}$ Department of Obstetrics and Gynecology, University Hospitals Leuven, Leuven, Belgium; \\ ${ }^{2}$ Department of Oncology, Leuven Cancer Institute, Laboratory of Tumor Immunology and Immunotherapy, \\ ImmunOvar Research Group, Catholic University of Leuven, Leuven, Belgium; \\ ${ }^{3}$ Department of Gynecology and Gynecologic Oncology, Kliniken Essen Mitte (KEM), Essen, Germany; \\ ${ }^{4}$ Department of Obstetrics and Gynecology, RZ Heilig Hart Tienen, Tienen, Belgium
}

\begin{abstract}
Uterine sarcomas are rare but very aggressive. Uterine myomas, on the other hand, are the most common benign tumors of the uterus. Currently there is no diagnostic technique available to distinguish them with certainty. This study aimed to summarize the published literature concerning protein-based biomarkers in the peripheral blood that can assist in this difficult differential diagnosis. In total, 48 articles, published between 1990 and 2017, were included. Most studies $(n=37)$ concerned soft tissue sarcomas, while 11 discussed uterine sarcomas specifically. Vascular endothelial growth factor (VEGF), basic fibroblast growth factor (bFGF), interleukins (IL), cancer antigen 125 (CA 125), lactate dehydrogenase, gangliosides $(L D H)$ and growth differentiation factor $15(G D F-15)$ are the most studied proteins in soft tissue sarcomas, including uterine sarcomas. Future research on improving sarcoma diagnosis should include these proteins.
\end{abstract}

Uterine sarcomas are rare gynecological neoplasms and account for approximately 3-7\% of uterine malignancies (1). They are mesenchymal tumors comprising leiomyosarcoma (LMS), endometrial stromal sarcoma (ESS), undifferentiated endometrial stromal sarcoma (UES) and adenosarcoma (AS). Carcinosarcoma (CSC) or malignant mixed müllerian tumor is now considered as a poorly differentiated epithelial tumor

This article is freely accessible online.

Correspondence to: An Coosemans MD, Ph.D., KU Leuven, Laboratory of Tumour Immunology and Immunotherapy, Onderwijs en Navorsing 1, box 603, Herestraat 49, 3000 Leuven, Belgium. Tel: +32 16304089, e-mail: an.coosemans@kuleuven.be

Key Words: Uterine sarcoma, biomarker, serum, diagnosis, immunosuppression, review. and will not be included in this review. Uterine sarcomas present with vague and non-specific symptoms due to their intramural localization. However, they are very aggressive and metastasize early. The overall survival is poor, especially for those having a high mitotic index. Reported 5-year survival rates are about $50 \%$ for FIGO stage I-II and only 20 and $10 \%$ for stage III and IV, respectively (2). Early diagnosis is hence very important, but a true challenge. A recent Norwegian cohort study of women diagnosed with uterine LMS showed that in $52 \%$ of patients, malignancy was not suspected at the time of surgery (3). It is a challenge, since approximately $70 \%$ of women develop uterine myomas (4). Although several features on ultrasound, computed tomography (CT) or magnetic resonance imaging (MRI) can raise suspicion, there is currently no diagnostic modality to distinguish between sarcomas and myomas with certainty (5). Sagae et al. (2014) showed that endometrial biopsy could diagnose LMS in only $35 \%$ and ESS in $25 \%$ of cases (6). Currently, no reliable predictive serum biomarkers have been identified. In daily practice, cancer antigen 125 (CA 125 ) is often used, however it is normally only significantly elevated in advanced disease. Therefore, it is a poor differential tool for uterine myomas and early-stage sarcomas $(7,8)$. Minimally invasive surgery is the surgical method of choice for myomas. Compared to open surgery, it is associated with less surgical complications, reduced blood loss, faster recovery, shorter hospital stays and fewer readmissions. During minimally invasive procedures, power morcellation is often required for tissue reduction. However, when a sarcoma is morcellated, proper pathological staging is precluded and tissue spilling within the abdominal cavity leading to local spread and recurrence may occur. In November 2014 the Food and Drug Administration (FDA) released a safety communication, discouraging the practice of morcellation of supposed myomas for oncological safety 
(9). This has led to a shift from minimally invasive surgery to open surgery with an increased economic burden and morbidity for patients with myomas. An American retrospective cohort study of 18,299 patients, undergoing hysterectomy for benign indications, analyzed the situation eight months after the FDA statement. They found a significant decrease of $4.1 \%$ in the use of laparoscopic hysterectomies and an increase in both abdominal and vaginal hysterectomies. This has led to a significant increase in major surgical complications from $2.2(\mathrm{n}=402)$ to $2.8 \%$ $(\mathrm{n}=512)$ and in readmission rate from 3.4 to $4.2 \%$ (10). Novel diagnostic methods capable of differentiating between myomas and sarcomas are needed for appropriate surgical planning. Protein biomarkers could form an interesting tool to help assessing the risk of uterine sarcoma in patients with presumed myomas. This study aimed to summarize the existing knowledge on biomarkers in the blood of sarcoma patients. Due to the low prevalence of uterine sarcomas, soft tissue sarcomas (STS) were also included in this analysis.

\section{Materials and Methods}

The PubMed database was used as a source. Search terms used were: uterine sarcoma, soft tissue sarcoma, marker, biomarker, diagnosis, serum, circulating, soluble, liquid biopsy, protein, immune and immunology. From the 2646 search results obtained in the period between 1990 and 2017, 419 abstracts were evaluated based on the title, 163 articles were read extensively, and 48 articles were eventually included. We included population-based studies that measured protein biomarkers in serum or plasma of soft tissue sarcoma patients, including uterine sarcomas. Articles on CSC only were excluded. Given the rarity of uterine sarcomas, studies were not limited by design, publication date or number of reported patients.

\section{Results}

A total of 37 studies in STS and 11 studies specifically in uterine sarcomas were identified. Results were divided in two main groups: cancer related and immune related protein biomarkers.

\section{Cancer-related protein biomarkers}

Role of cancer related protein biomarkers in cancer. CA 125 is a membrane glycoprotein associated with the coelomic epithelium, including the epithelium of the female reproductive tract. It is used as a tumor marker in the followup of ovarian cancer but has been shown to be non-specific [e.g. elevated in benign abdominal conditions, such as endometriosis (11), and in cardiac failure (12)]. Lactate dehydrogenase (LDH) is a pyridine-linked enzyme catalyzing the reduction of free pyruvate to lactate during glycolysis. Malignant cells proliferate rapidly and display an increased rate of glycolysis, independently of oxygen availability (Warburg effect). Furthermore, following cell damage, intracellular LDH leaks into the bloodstream (13).
Insulin growth factor binding protein 7 (IGFBP7), also termed IGFBP-related protein-1, is a cell adhesive glycoprotein, mainly synthesized in the liver. Both increased and decreased expression of IGFBP7 have been reported in different malignancies, suggesting a complex role in cancer (14). Tumor cell gangliosides are cell surface glycolipids, that are overexpressed in solid tumors and are shed in greater quantities into the tumor microenvironment (15). Cadherins are cell-to-cell adhesion proteins, affecting tissue morphogenesis and structure. Tumor cells show decreased cadherin-mediated intercellular adhesions. This results in a loss of epithelial structure and gain of migratory capacity, potentiating invasion and metastasis. They are cleaved from the cell surface and released as soluble cadherins in serum $(16,17)$. The invasive capacity of tumor cells is related to the presence of matrix metalloproteinases that degrade extracellular matrix components and basement membranes. They are inhibited through endogenous specific tissue inhibitors of matrix metalloproteinases (TIMPs) (18).

Relevance of cancer-related protein biomarkers in the diagnosis of sarcomas. Table I gives an overview of studied non-immune related markers that have a potential role in the diagnosis of sarcomas. The most studied marker is CA 125 . Three out of five studies have shown significantly higher CA 125 levels in the uterine sarcoma group compared to the patients with myomas $(8,19-22)$. Three studies have found statistically higher preoperative serum LDH levels in the uterine sarcoma group compared to patients with myomas (21-23) and two prospective studies showed significantly higher LDH levels in children with STS compared to healthy children $(24,25)$. One study found that patients with uterine myomas $(n=24)$ had elevated serum LDH values, although this was not significant compared to serum levels in healthy controls $(n=14)(26)$. In addition, three studies demonstrated that the combined use of serum LDH levels with different imaging modalities (fluor-18-deoxyglucose positron emission tomography (FDG-PET), PET-CT or MRI) increased the sensitivity and specificity of the preoperative diagnosis of uterine sarcomas and myomas, respectively $(21,22,27)$. Nagai et al. (2015), proposed a preoperative diagnosis scoring system for uterine sarcomas [the PREoperative Sarcoma Score (PRESS)] using age at diagnosis, serum LDH levels, MRI findings, and endometrial cytology findings and revised it a year later (revised PRESS=rPRESS) (23). In the multivariate analysis of the original PRESS, MRI findings were not an independent predictive factor and hence were eliminated from the revised version, resulting in a better diagnostic accuracy. Table II shows an overview of the rPRESS. Patients were at higher risk for a sarcoma when their score was four or higher. The scoring system yielded an accuracy, sensitivity and specificity of $94 \%, 80 \%$ and $98 \%$, respectively (23). Serum levels of gangliosides, soluble 
Table I. Overview of studied cancer-related protein biomarkers in serum or plasma in STS (including USC).

\begin{tabular}{|c|c|c|c|}
\hline Marker & Tumor type $[\mathrm{N}]$ & Controls $[\mathrm{N}]$ & Increased levels at diagnosis ( $p$-Value)* \\
\hline \multirow[t]{5}{*}{ CA $125(8,19,20-22)$} & LMS [42] & UM [84] & $p<0.001$ \\
\hline & USC [26] & UM [815] & $p<0.005$ \\
\hline & USC [55] & UM [165], adenomyosis [165] & $p<0.01$ \\
\hline & USC [10] & UM [24] & NS \\
\hline & USC [15] & UM [19] & NS \\
\hline \multirow[t]{5}{*}{ LDH (21-25) } & LMS [10] & UM [15] & $p=0.0093$ \\
\hline & USC [15] & UM [19] & $p=0.001$ \\
\hline & USC [15] & UM [48] & $p<0.001$ \\
\hline & STS [30] & Healthy children $[30]$ & $p=0.0202$ \\
\hline & STS [35] & Healthy children $[50]$ & $p<0.001$ \\
\hline Gangliosides (28) & STS [97] & Healthy controls [39] & $p=0.001$ \\
\hline sN-CAD (29) & Sarcoma $[73]^{\circ}$ & Healthy controls [87] & $p<0.01$ \\
\hline IGFBP7 (30) & STS [59] & Healthy controls [10] & $p<0.0005$ \\
\hline TIMP1, 2 (31) & STS [53] & Healthy controls [56] & $p=0.0001, p=0.0001$ \\
\hline
\end{tabular}

CA 125: Cancer antigen 125; LDH: lactate dehydrogenase; sN-CAD: soluble neural-cadherin; IGFBP7: insulin growth factor binding protein 7; TIMP: tissue inhibitors of matrix metalloproteinases; LMS: leiomyosarcoma; UM: uterine myoma; USC: uterine sarcoma; STS: soft tissue sarcoma. *Except for TIMP1,2: decreased serum levels at diagnosis; ${ }^{\circ} 23$ malignant bone tumors and 50 STS.

Table II. Overview of the revised PREoperative Sarcma Score (rPRESS).

\begin{tabular}{lcc}
\hline Predictive factors & Cut-off values & Score on 10 points \\
\hline Age at diagnosis & $\geq 49$ years & 2 \\
Serum LDH levels & $\geq 279$ U/1 & 4 \\
Endometrial cytology & $\geq$ Class III (the Papanicolaou classification)* & 4 \\
\hline
\end{tabular}

LDH: Lactate dehydrogenase. *If Class III or higher was observed, an endometrial biopsy was performed. Patients who were diagnosed with a malignant tumor at this point were excluded from the present study.

neural-cadherin (sN-CAD) and IGFBP7 were significantly elevated and levels of TIMP1/2 significantly decreased in sarcoma patients compared to healthy controls. However, only a limited number of studies are available for these biomarkers (28-31).

\section{Immune-related protein biomarkers}

Role of immune-related proteins in cancer. Over the past years, the role of the immune system in cancer has become established. Tumor cells can be recognized and eliminated by both the adaptive and innate immune response. If cancerous cells are not eliminated, an equilibrium phase is established. Neoplastic cells remain present, but are constantly regulated by the immune system. During this process, tumor cells can lose tumor-associated antigens, while the tumor microenvironment can become more immunosuppressive and thereby the tumor can escape immune control. Immunosuppressive cells are attracted towards the tumor side (myeloid derived suppressor cells, regulatory $\mathrm{T}$ cells, M2 macrophages, etc.) and can even promote tumor growth $(32,33)$. Based on this theory, we can assume that cytokines, interleukins and chemokines, produced by these immune cells will be influenced by the malignant disease. Malignant cells can directly inhibit immune cell functions (by tumor growth factor $\beta$ (TGF- $\beta$ ), interleukin (IL)-10, soluble IL-2 receptor $\alpha$ (sIL-2R $\alpha$ ), vascular endothelial growth factor (VEGF), etc.) or stimulate a pro-inflammatory environment (by IL-2, IL-6, IL-8 IL-12, IL-23, granulocyte colony-stimulating factor (G-CSF), macrophage colony-stimulating factor (M-CSF), tumor necrosis factor $\alpha$ (TNF $\alpha)$, etc.) (34). Tumor-promoting inflammation, mainly induced by innate immune cells, is considered one of the hallmarks of cancer (17). Clinical markers reflecting the inflammatory status of a patient are C-reactive protein (CRP) and erythrocyte sedimentation rate (ESR). CRP is an acute-phase protein and its production in hepatocytes is induced following the elevation of IL-6 in response to stressors, such as infection or tissue damage (32). Several possible mechanistic links between elevated CRP levels and cancer have been proposed. On one hand, it could be a direct result of a growing tumor, causing inflammation. On the other hand, it might be mediated by the innate 
Table III. Overview of studied immune-related protein biomarkers in serum or plasma in STS (including USC).

\begin{tabular}{|c|c|c|c|}
\hline Marker & Tumor type $[\mathrm{N}]$ & Controls $[\mathrm{N}]$ & Increased levels at diagnosis ( $p$-Value) \\
\hline \multirow[t]{9}{*}{ VEGF $(37,40-47)$} & STS [25] & Healthy controls [34] & $p=0.0002$ \\
\hline & STS [145] & Healthy controls [50] & $p<0.001$ \\
\hline & STS [156] & Healthy controls [50] & $p<0.001$ \\
\hline & STS [85] & Healthy controls [18] & $p=0.0001$ \\
\hline & STS [76] & Healthy controls [15] & $p<0.0001$ \\
\hline & STS [94] & BSTT [29] & $\begin{array}{l}\text { Grade 1: NS, grade } 2: p=0.007 \\
\text { grade } 3: p=0.003\end{array}$ \\
\hline & STS [108] & Healthy controls [30] & $p<0.05$ \\
\hline & RMS [17] & Healthy children [34] & $p=0.013$ \\
\hline & STS [21] & Healthy controls [25] & NS: $p>0.05$ \\
\hline \multirow[t]{6}{*}{ bFGF $(37,40-43,45)$} & STS [25] & Healthy controls [34] & $p=0.0001$ \\
\hline & STS [145] & Healthy controls [50] & $p<0.001$ \\
\hline & STS [156] & Healthy controls [50] & $p<0.001$ \\
\hline & STS [85] & Healthy controls [18] & $p=0.0001$ \\
\hline & STS [76] & Healthy controls [15] & $p<0.001$ \\
\hline & STS [108] & Healthy controls [30] & $p<0.05$ \\
\hline CRP (24) & STS [30] & Healthy children $[30]$ & $p<0.00001$ \\
\hline Hs-CRP (51) & STS [60] & BSTT [35], healthy controls [10] & $p<0.0001$ \\
\hline ESR (24) & STS [30] & Healthy children [30] & $p<0.00001$ \\
\hline \multirow[t]{2}{*}{ IL-1ra $(40,41)$} & STS [145] & Healthy controls [50] & $p<0.001$ \\
\hline & STS [156] & Healthy controls [50] & $p<0.001$ \\
\hline \multirow[t]{4}{*}{ sIL-2R $\alpha(25,40,41,48)$} & STS [35] & Healthy children [50] & $p<0.001$ \\
\hline & STS [145] & Healthy controls [50] & $p<0.001$ \\
\hline & STS [156] & Healthy controls [50] & $p<0.005$ \\
\hline & STS [8] & Healthy children [30] & $p<0.001$ \\
\hline B2-M (25) & STS [35] & Healthy children [50] & NS \\
\hline \multirow[t]{3}{*}{ IL-6 $(40,41,50)$} & STS [145] & Healthy controls [50] & $p<0.001$ \\
\hline & STS [156] & Healthy controls [50] & $p<0.001$ \\
\hline & STS [59] & BSTT [40] & $p<0.0001$ \\
\hline \multirow[t]{2}{*}{ sIL-6R $(40,41)$} & STS [145] & Healthy controls [50] & NS \\
\hline & STS [156] & Healthy controls [50] & NS \\
\hline \multirow[t]{2}{*}{ IL-8 $(40,41)$} & STS [145] & Healthy controls [50] & $p<0.001$ \\
\hline & STS [156] & Healthy controls [50] & $p<0.001$ \\
\hline \multirow[t]{4}{*}{ IL-10 $(24,40,41,49)$} & STS [30] & Healthy children [30] & $p=0.0130$ \\
\hline & STS [145] & Healthy controls [50] & $p<0.001$ \\
\hline & STS [156] & Healthy controls [50] & $p<0.001$ \\
\hline & STS [59] & Healthy children [30] & $p=0.0027$ \\
\hline \multirow[t]{2}{*}{ IL-12 $(24,49)$} & STS [30] & Healthy children [30] & $p=0.0403$ \\
\hline & STS [59] & Healthy children [30] & $p=0.0320$ \\
\hline \multirow[t]{2}{*}{ G-CSF $(40,41)$} & STS [145] & Healthy controls [50] & NS \\
\hline & STS [156] & Healthy controls [50] & NS \\
\hline \multirow[t]{2}{*}{ M-CSF $(40,41)$} & STS [145] & Healthy controls [50] & $p<0.001$ \\
\hline & STS [156] & Healthy controls [50] & $p<0.05$ \\
\hline \multirow[t]{2}{*}{ TNF $\alpha$, TNFRI, II $(40,41)$} & STS [145] & Healthy controls [50] & $p<0.001$ \\
\hline & STS [156] & Healthy controls [50] & $p<0.001$ \\
\hline Angiopoietin 2 (45) & STS [108] & Healthy controls [30] & $p<0.05$ \\
\hline \multirow[t]{2}{*}{ Endostatin $(37,43)$} & STS [25] & Healthy controls [34] & $p=0.0002$ \\
\hline & STS [76] & Healthy controls [15] & NS \\
\hline Leptin (45) & STS [108] & Healthy controls [30] & NS \\
\hline DR6 (58) & Sarcomas $[71]^{\circ}$ & Healthy controls [39] & $p<0.001$ \\
\hline TGF- $\beta(59)$ & Solid tumors $[66]^{*}$ & Healthy children [15] & $p=0.015$ \\
\hline GDF-15 (60) & USC [19] & UM [50], healthy controls [40] & $p=0.007, p=0.002$ \\
\hline
\end{tabular}

IL-1ra: Interleukin-1 receptor antagonist; sIL-2R $\alpha$ : soluble IL-2 receptor $\alpha$; B2-M: beta-2-microglobulin; IL: interleukin; sIL-6R: soluble interleukin 6 receptor; G-CSF: granulocyte colony-stimulating factor; TNF $\alpha$ : tumor necrosis factor $\alpha$; TNF: tumor necrosis factor receptor; M-CSF: macrophage colony-stimulating factor; Hs-CRP: high sensitivity c-reactive protein; ESR: erythrocyte sedimentation rate; VEGF: vascular endothelial growth factor; bFGF: basic fibroblast growth factor; TGF- $\beta$ : transforming growth factor $\beta$; DR6: death receptor 6; GDF-15: growth differentiation factor15; STS: soft tissue sarcoma; BSTT: benign soft tissue tumors; RMS: rhabdomyosarcoma; USC: uterine sarcoma; UM: uterine myoma. *17 STS, 17 osteosarcoma, 14 Ewing's sarcoma, 12 neuroblastoma, 2 germ cell tumors, 2 hepatoblastomas, 1 Wilms' tumor, 1 nasopharynx cancer. ${ }^{\circ} 58$ STS, 4 osteosarcomas, 3 extraskeletal myxoid chondrosarcomas, 1 Ewing's sarcoma and 6 not otherwise specified. 
Table IV. Overview of studied protein biomarkers in uterine sarcoma in serum or plasma.

\begin{tabular}{|c|c|c|c|}
\hline Marker & Tumor type $[\mathrm{N}]$ & Controls $[\mathrm{N}]$ & Increased levels at diagnosis (p-Value) \\
\hline \multirow{5}{*}{ CA $125(8,19-22)$} & LMS [42] & UM [84] & $p<0.001$ \\
\hline & USC [26] & UM [815] & $p<0.005$ \\
\hline & USC [55] & UM [165], adenomyosis [165] & $p<0.01$ \\
\hline & USC [10] & UM [24] & NS \\
\hline & USC [15] & UM [19] & NS \\
\hline \multirow[t]{3}{*}{ LDH (21-23) } & LMS [10] & UM [15] & $p=0.0093$ \\
\hline & USC [15] & UM [19] & $p=0.001$ \\
\hline & USC [15] & UM [48] & $p<0.001$ \\
\hline GDF-15 (60) & USC [19] & UM [50], healthy controls [40] & $p=0.007, p=0.002$ \\
\hline
\end{tabular}

CA 125: Cancer antigen 125; LDH: lactate dehydrogenase; NLR: neutrophil-to-lymphocyte ratio; GDF-15: growth differentiation factor-15; LMS: leiomyosarcoma; UM: uterine myoma; USC: uterine sarcoma.

immune system. Finally, cancer cells can increase the production of inflammatory cytokines, which may induce CRP production (35).

As a side note, we want to stress the relevance of the neutrophil-to-lymphocyte ratio (NLR) as a diagnostic tool in sarcomas. This ratio has growing relevance in the diagnosis of several cancer types and in identifying patients with poor prognosis. Neutrophils are associated with the innate immune system and are often involved in immunosuppression (by suppressing the cytolytic activity of immune cells such as lymphocytes, activated $\mathrm{T}$ cells, and natural killer cells). The number of lymphocytes mirrors the effective adaptive immune system. Therefore, the NLR reflects the equilibrium between immunosuppression and immune activation. An elevated NLR represents an increase in the immunosuppressive status (36).

Tumor neovascularization, generated by the process of angiogenesis, is essential for the supply of nutrients and oxygen to the fast-growing tumor cells (17). VEGF and basic fibroblast growth factor (bFGF) promote angiogenesis. In addition to the production of pro-angiogenic cytokines, there is some evidence that STS can also release anti-angiogenic proteins, such as endostatin (37).

Death receptor 6 (DR6) belongs to the TNF receptor family and plays a key role in apoptosis induction. Yang et al. (2016), demonstrated that DR6 facilitates tumor growth by increasing angiogenesis through releasing IL-6 and VEGF-A (38). Growth differentiation factor-15 (GDF-15), also known as macrophage inhibitory cytokine-1, is a distant member of the TGF- $\beta$ family. As a p53-regulated cytokine, it has been shown to have a role in the stress response of cells after cellular injury, for example in inflammation and cancer (39).

Relevance of immune related protein biomarkers in the diagnosis of sarcomas. Table III gives an overview of the studied immune related markers for sarcomas. Two prospective studies explored the pretreatment serum levels of several cytokines and soluble cytokine receptors in patients with STS compared to healthy controls. Both found significantly elevated pretreatment levels of 11 out of 13 tested cytokines and soluble receptors in the sarcoma group: interleukin-1 receptor antagonist (IL-1 ra), sIL-2Ra, IL-6, IL8, IL-10, TNF $\alpha$, tumor necrosis factor receptor (TNF R) I and II, M-CSF, VEGF and bFGF. Soluble interleukin 6 receptor (sIL-6R) and G-CSF showed no significant changes in serum levels in the sarcoma group $(40,41)$. Serum levels of IL-1ra, IL-6, IL-8, Il-10, TNF RII and M-CSF decreased significantly after radical surgery in patients without metastases and after chemotherapy in patients with metastases $(p=0.001)$ (41). Most studied immune related markers in STS are VEGF and $b F G F$. Eight and six studies reported significantly elevated serum VEGF and bFGF levels, respectively, in patients with STS compared to patients with benign soft tissue tumors or healthy controls (37, 40-46), while one study did not find a significant elevation in serum VEGF levels (47). Significantly elevated sIL-2Ra, IL-6 and IL-10 levels in the sarcoma group compared to healthy controls or patients with benign soft tissue tumors were found in four, three and four studies, respectively $(24,25,40,41,48-50)$. Two studies reported significantly higher serum CRP levels in the STS group compared to benign soft tissue tumors and healthy controls $(24,51)$. In a study of $332 \mathrm{STS}$ patients, the authors reported elevated CRP levels in $41 \%$ using a cut-off value of $0.1 \mathrm{mg} / \mathrm{dl}$ (52). Three other studies on 142, 102 and 162 STS patients, reported CRP levels $>0.3 \mathrm{mg} / \mathrm{dl}$ in $25 \%,>0.3 \mathrm{mg} / \mathrm{dl}$ in $18 \%$, and $\geq 0.2 \mathrm{mg} / \mathrm{dl}$ in $41 \%$ of patients, respectively (53-55). ESR has been limitedly studied. One study showed significantly elevated ESR levels in children with STS compared to healthy children (24).

Furthermore, one retrospective study has found a significantly elevated NLR in the STS group $(n=83)$ compared to benign soft tissue tumors $(\mathrm{n}=140)(p<0.001)$ (56). In addition, two studies found significantly elevated 
NLR levels in the uterine sarcoma group compared to patients with myomas $(20,57)$. These two studies will be discussed in the next section.

DR6 and TGF- $\beta$ have been limitedly studied in sarcomas. One study found significantly elevated DR6 levels in sarcoma patients compared to healthy controls (58) and one study found significantly elevated TGF- $\beta$ in solid tumors, including 17 STS, compared to healthy controls (59).

Protein biomarkers in uterine sarcomas. Table IV gives an overview of available studies on protein biomarkers in uterine sarcomas specifically. Three out of five studies showed significantly higher serum CA 125 levels in the sarcomas group compared to patients with myomas $(8,19$ 22). Duk et al. (1994) analyzed pretreatment CA 125 levels in 30 patients with uterine sarcomas and found that only $40 \%$ had elevated serum levels (>16 U/ml) (7). Two studies found that there was a significant overlap regarding CA 125 levels between the early stage uterine sarcoma and myoma group $(8,19)$. Furthermore, three studies found statistically higher pretreatment serum LDH levels in the sarcoma group compared to patients with myoma (21-23). Kim et al. (2010) compared 55 patients with uterine sarcomas (21 CSC, 20 LMS and 14 ESS) to 165 with uterine myomas and 165 with adenomyosis in terms of age, body mass index and uterine volume and demonstrated that the preoperative blood NLR and neutrophil count were significantly higher, and the lymphocyte count significantly lower in the uterine sarcoma group compared to the myoma and adenomyosis group. Moreover, they observed a stronger predictive value of NLR compared to CA 125 (sensitivity, $74.5 \%$ vs. $52.3 \%$; specificity, $70.3 \%$ vs. $50.5 \% ; p<0.05)$ (20). Cho et al. (2015) compared 31 women with uterine sarcomas (14 ESS, 11 LMS, 6 USS) to 93 with uterine myomas and found statistically higher preoperative NLR values in the sarcoma group (57). Trovik et al., studied 19 patients with uterine sarcomas (13 LMS, four ESS, one AS and one USS), 50 with uterine myomas and 40 healthy controls and demonstrated a significantly higher median GDF-15 plasma concentration in the sarcoma group compared to the myoma group and healthy controls (60).

\section{Discussion}

The preoperative diagnosis of sarcomas limited to the uterus remains very challenging. For oncological safety, many women with myomas undergo open surgery instead of laparoscopic surgery, resulting in an increased morbidity and economic burden. On the other hand, minimally invasive surgery with morcellation of presumed benign myomas may lead to intra-abdominal spread of an unexpected sarcoma, resulting in poor survival. Proteins in serum or plasma are a potential tool to improve the preoperative diagnosis of uterine sarcomas. Measurement is easy, non-invasive and relatively inexpensive. The aim of this review was to give an overview of the existing literature on diagnostic biomarkers in uterine sarcomas. We have included 48 studies. Since uterine sarcomas are a subgroup of STS and information on uterine sarcomas only was very limited (only 11 studies), we have also included studies on non-uterine STS (37 studies).

It has become evident that the immune system has, besides its host-protective role, an influence on the development, progression and metastasis of cancers. The immune profiles in the tumor microenvironment of several types of sarcomas is a growing field of research. For example, Chen et al. (2018), found a possible role of the IL33/IL-1 receptor-like 1 (ST2) axis in enhancing antitumor immunity in STS (61). More and more immunomodulatory drugs are being developed. For example, Ratti et al. (2017), demonstrated a decrease in monocytic myeloid derived suppressor cells in the tumor microenvironment (62). This review demonstrates the growing number of circulating protein biomarkers studied in the diagnosis of sarcomas. Most studied immune related biomarkers are VEGF, bFGF and interleukins. Despite the important role of TGF- $\beta$ in immunosuppression in several other solid cancers (34), we found only one retrospective study measuring serum TGF$\beta$ levels in 17 STS among 66 different solid tumors (59). The median serum TGF- $\beta$ levels at the time of diagnosis were higher in all groups compared to healthy controls. Despite the limited number of studies in sarcoma populations, NLR, representing an increase in the immunosuppressive status, may form an interesting diagnostic marker. Most studies on solid tumor biomarkers, specifically in uterine sarcomas, have examined CA 125 , NLR, LDH and GDF-15. CA 125 is commonly measured in uterine sarcomas, but its usefulness is controversial due to the lack of specificity.

Given the small sample size, the mixture of various cancer types and the retrospective nature of many studies, the data should be interpreted with caution. Some studies performed in children may have a different tumor and immune biology $(24,25,46,48,49,59)$. Also, children have less comorbidities potentially affecting the proteins' serum levels. Most studies also compare STS or uterine sarcomas to healthy controls instead of to benign soft tissue tumors or uterine myomas, which does not reflect clinical reality. Furthermore, the markers' sensitivity and specificity are limited. Therefore, they would most likely benefit diagnosis in combination with other diagnostic modalities (such as ultrasound and MRI).

To the best of our knowledge, this is the first review on protein-based biomarkers in the blood of sarcoma patients. Although the number of available studies on protein-based biomarkers in uterine sarcomas is limited, interleukins, 
VEGF, bFGF, CA 125, LDH, gangliosides and GDF-15 are the most studied and significantly altered proteins in STS, including uterine sarcomas, compared to healthy controls, benign soft tissue tumors or uterine myomas. Further research to improve the sensitivity of preoperative uterine sarcoma diagnosis using multiplex assays should preferentially include these biomarkers.

\section{Conflicts of Interest}

The Authors declare no conflict of interest regarding this study.

\section{Author's Contributions}

NG performed the literature search, database set up and contributed to the writing of the manuscript. TB reviewed the manuscript. TvdB contributed to the study design and reviewed the manuscript. AC contributed to the study design, the writing of the manuscript and reviewed the manuscript. All authors are in agreement will all aspects of the final manuscript.

\section{References}

1 D'Angelo E and Prat J: Uterine sarcomas: A review. Gynecol Oncol 116(1): 131-139, 2010. PMD: 19853898. DOI: 10.1016/ j.ygyno.2009.09.023

2 Amant F, Coosemans A, Debiec-Rychter M, Timmerman D and Vergote I: Clinical management of uterine sarcomas. Lancet Oncol 10: 1188-1198, 2009. PMID: 19959075. DOI: 10.1097/ igc. 0000000000000037

3 Skorstad M, Kent A and Lieng M: Preoperative evaluation in women with uterine leiomyosarcoma. A nationwide cohort study. Acta Obstet Gynecol Scand 95(11): 1228-1234, 2016. PMID: 27564388. DOI: $10.1111 /$ aogs. 13008

4 Walker CL and Stewart EA: Uterine fibroids: The elephant in the room. Science 308(5728): 1589-1592, 2005. PMID: 1594 7177. DOI: $10.1126 /$ science. 1112063

5 Van den Bosch T, Coosemans A, Morina M, Timmerman D and Amant F: Screening for uterine tumours. Best Pract Res Clin Obstet Gynaecol 26(2): 257-266, 2012. PMID: 22078749. DOI: 10.1016/j.bpobgyn.2011.08.002

6 Sagae S, Yamashita K, Ishioka S, Nishioka Y, Terasawa K, Mori M, Yamashiro K, Kanemoto $\mathrm{T}$ and Kudo R: Preoperative Diagnosis and Treatment Results in 106 Patients with Uterine Sarcoma in Hokkaido, Japan. Oncology 67(1): 33-39, 2004. PMID: 15459493. DOI: 10.1159/000080283

7 Duk JM, Bouma J, Burger GTN, Nap M and De Bruijn HW: CA 125 in serum and tumor from patients with uterine sarcoma. Int J Gynecol Cancer 4(3): 156-160, 1994. PMID: 11578400. DOI: 10.1046/j.1525-1438.1994.04030156.x

8 Juang CM, Yen SM, Horng CH, Twu NF, Yu HC and Hsu WL: Potential role of preoperative serum CA125 for the differential diagnosis between uterine leiomyoma and uterine leiomyosarcoma. Eur J Gynaecol Oncol 27(4): 370-374, 2006. PMID: 17009628 .

9 Stephenson J: FDA warns against procedure used in removing fibroids. JAMA 311(19): 1956, 2014. PMID. 24846021. DOI: $10.1001 /$ jama.2014.5182
10 Harris JA, Swenson CW, Uppal S, Kamdar N, Mahnert N, AsSanie S and Morgan DM: Practice patterns and postoperative complications before and after US Food and Drug Administration safety communication on power morcellation. Am J Obstet Gynecol 214(1): 98.e1-13, 2016. PMID. 26314519. DOI: 10.1016/ j.ajog.2015.08.047

11 Bottoni P and Scatena R: The Role of CA 125 as Tumor Marker: Biochemical and Clinical Aspects. In: Advances in Cancer Biomarkers. Scatena R (eds.). Dordrecht, Springer Netherlands, pp. 229-244, 2015.

12 Zhuang J, Faggiano P, Li Q, Pradelli D, Med V, Peng W, Zuo M and $\mathrm{Xu}$ Y: Insights into the clinical implications of carbohydrate antigen 125 as a biomarker of heart failure: A meta-analysis and systematic review of published studies. J Cardiovasc Med 15(12): 864-872, 2014. PMID: 25353973. DOI: 10.2459/ JCM. 0000000000000051

13 Jurisic V, Radenkovic S and Konjevic G: The actual role of LDH as tumor marker, biochemical and clinical aspects. In: Advances in Cancer Biomarkers. Scatena R (eds.). Dordrecht: Springer Netherlands, pp. 115-124, 2015.

14 Gambaro K, Quinn MCJ, Cáceres-Gorriti KY, Shapiro RS, Provencher D, Rahimi K, Mes-Masson AM and Tonin PN: Low levels of IGFBP7 expression in high-grade serous ovarian carcinoma is associated with patient outcome. BMC Cancer 15: 135, 2015. PMID: 25886299. DOI: $10.1186 / \mathrm{s}$ 12885-015-1138-8

15 Krengel $U$ and Bousquet PA: Molecular recognition of gangliosides and their potential for cancer immunotherapies. Front Immunol 5: 325, 2014. PMID: 25101077. DOI: 10.3389/ fimmu.2014.00325

16 De Wever O, Derycke L, Hendrix A, De Meerleer G, Godeau F, Depypere $\mathrm{H}$ and Bracke $\mathrm{M}$ : Soluble cadherins as cancer biomarkers. Clin Exp Metastasis 24(8): 685-697, 2007. PMID: 17952616. DOI: 10.1007/s10585-007-9104-8

17 Hanahan D and Weinberg Robert A: Hallmarks of cancer: The next generation. Cell 144(5): 646-674, 2011. PMID: 21376230. DOI: $10.1016 /$ j.cell.2011.02.013

18 Bodnar M, Szylberg Ł, Kazmierczak W and Marszalek A: Tumor progression driven by pathways activating matrix metalloproteinases and their inhibitors. J Oral Pathol Med 44(6): 437-443, 2014. PMID: 25244188. DOI: 10.1111/jop.12270

19 Yilmaz N, Sahin I, Kilic S, Ozgu E, Gungor T and Bilge U: Assessment of the predictivity of preoperative serum CA 125 in the differential diagnosis of uterine leiomyoma and uterine sarcoma in the Turkish female population. Eur J Gynaecol Oncol 30(4): 412-414, 2009. PMID: 19761133.

20 Kim HS, Han KH, Chung HH, Kim JW, Park NH, Song YS and Kang SB: Neutrophil to lymphocyte ratio for preoperative diagnosis of uterine sarcomas: A case-matched comparison. Eur J Surg Oncol 36(7): 691-698, 2010. PMID: 20570475. DOI: $10.1016 /$ j.ejso.2010.05.004

21 Nagamatsu A, Umesaki N, Li L and Tanaka T: Use of F-18fluorodeoxyglucose positron emission tomography for diagnosis of uterine sarcomas. Oncology reports 23: 1069-1076, 2010. PMID: 20204293. DOI: 10.3892/or_00000734

22 Kusunoki S, Terao Y, Ujihira T, Fujino K, Kaneda H, Kimura M, Ota T and Takeda S: Efficacy of PET/CT to exclude leiomyoma in patients with lesions suspicious for uterine sarcoma on MRI. Taiwan J Obstet Gynecol 56(4): 508-513, 2017. PMID: 28805609. DOI: $10.1016 /$ j.tjog.2017.05.003 
23 Nagai T, Takai Y, Akahori T, Ishida H, Hanaoka T, Uotani T, Sato S, Matsunaga S, Baba K and Seki H: Highly improved accuracy of the revised PREoperative sarcoma score (rPRESS) in the decision of performing surgery for patients presenting with a uterine mass. SpringerPlus 4: 520, 2015. PMID: 2640 5640. DOI: $10.1186 / \mathrm{s} 40064-015-1318-7$

24 Bien E, Balcerska A, Adamkiewicz-Drozynska E, Rapala M, Krawczyk M and Stepinski J: Pre-treatment serum levels of interleukin-10, interleukin-12 and their ratio predict response to therapy and probability of event-free and overall survival in childhood soft tissue sarcomas, Hodgkin's lymphomas and acute lymphoblastic leukemias. Clin Biochem 42(10): 11441157, 2009. PMID: 19376105. DOI: 10.1016/j.clinbiochem. 2009.04.004

25 Bien E, Rapala M, Krawczyk M and Balcerska A: The serum levels of soluble interleukin-2 receptor alpha and lactate dehydrogenase but not of B2-microglobulin correlate with selected clinico-pathological prognostic factors and response to therapy in childhood soft tissue sarcomas. J Cancer Res Clin Oncol 136(2): 293-305, 2010. PMID: 19693535. DOI: 10.1007/ s00432-009-0661-x

26 Koukourakis MI, Kontomanolis E, Giatromanolaki A, Sivridis E and Liberis V: Serum and tissue LDH levels in patients with breast/gynaecological cancer and benign diseases. Gynecol Obstet Invest 67(3): 162-168, 2009. PMID: 19088479. DOI: $10.1159 / 000183250$

27 Goto A, Takeuchi S, Sugimura K and Maruo T: Usefulness of Gd-DTPA contrast-enhanced dynamic MRI and serum determination of LDH and its isozymes in the differential diagnosis of leiomyosarcoma from degenerated leiomyoma of the uterus. Int J Gynecol Cancer 12(4): 354-361, 2002. PMID: 12144683

28 Perez CA, Ravindranath MH, Soh D, Gonzales A, Ye W and Morton DL: Serum Anti-Ganglioside IgM Antibodies in Soft Tissue Sarcoma: Clinical Prognostic Implications. Cancer J 8(5): 384-392, 2002. PMID: 12416896.

29 Niimi R, Matsumine A, Iino T, Nakazora S, Nakamura T, Uchida A and Sudo A: Soluble Neural-cadherin as a novel biomarker for malignant bone and soft tissue tumors. BMC Cancer 13: 309, 2013. PMID: 23799912. DOI: 10.1186/1471-2407-13-309.

30 Benassi MS, Pazzaglia L, Novello C, Quattrini I, Pollino S, Magagnoli G, Picci P and Conti A: Tissue and serum IGFBP7 protein as biomarker in high-grade soft tissue sarcoma. Am J Cancer Res 5(11): 3446-3454, 2015. PMID: 26807324.

31 Benassi M, Magagnoli G, Ponticelli F, Pazzaglia L, Zanella L, Gamberi G, Ragazzini P, Ferrari C, Mercuri $M$ and Picci P: Tissue and serum loss of metalloproteinase inhibitors in high grade soft tissue sarcomas. Histol Histopathol 18: 1035-1040, 2003. PMID: 12973672. DOI: 10.14670/HH-18.1035

32 Schreiber RD, Old LJ and Smyth MJ: Cancer immunoediting: Integrating immunity's roles in cancer supression and promotion. Science 331: 1565-1570, 2011. PMID: 21436444. DOI: 10.1126/ science. 1203486

33 Vesely MD, Kershaw MH, Schreiber RD and Smyth MJ: Natural innate and adaptive immunity to cancer. Annu Rev Immunol 29(1): 235-271, 2011. PMID: 21219185. DOI: 10.1146/annurevimmunol-031210-101324

34 Lippitz BE: Cytokine patterns in patients with cancer: a systematic review. Lancet Oncol 14(6): e218-e228, 2013. PMID: 23639322. DOI: 10.1016/S1470-2045(12)70582-X
35 Allin $\mathrm{KH}$ and Nordestgaard BG: Elevated C-reactive protein in the diagnosis, prognosis, and cause of cancer. Crit Rev Clin Lab Sci 48(4): 155-170, 2011. PMID: 22035340. DOI: $10.3109 /$ 10408363.2011.599831

36 Baert T, Van Camp J, Vanbrabant L, Busschaert P, Laenen A, Han S, Van Nieuwenhuysen E, Vergote I and Coosemans A: Influence of CA125, platelet count and neutrophil to lymphocyte ratio on the immune system of ovarian cancer patients. Gynecol Oncol 150(1): 31-37, 2018. PMID: 29751991. DOI: 10.1016/ j.ygyno.2018.05.004

37 Feldman AL, Pak H, Yang JC, Alexander RH and Libutti SK: Serum endostatin levels are elevated in patients with soft tissue sarcoma. Cancer 91(8): 1525-1529, 2001. DOI: 10.1002/10970142(20010415)91:8<1525::AID-CNCR 1161>3.0.CO;2-P

38 Yang X, Shi B, Li L, Xu Z, Ge Y, Shi J, Liu Y and Zheng D: Death receptor 6 (DR6) is required for mouse B16 tumor angiogenesis via the NF-kB, P38 MAPK and STAT3 pathways. Oncogenesis 5(3): e206, 2016. PMID: 26950598. DOI: 10.1038/oncsis.2016.9

39 Unsicker K, Spittau B and Krieglstein K: The multiple facets of the TGF- $\beta$ family cytokine growth/differentiation factor15/macrophage inhibitory cytokine-1. Cytokine Growth Factor Rev 24(4): 373-384, 2013. PMID: 23787157. DOI: 10.1016/ j.cytogfr.2013.05.003

40 Ruka W, Rutkowski P, Kaminska J, Rysinska A and Steffen J: Alterations of routine blood tests in adult patients with soft tissue sarcomas: relationships to cytokine serum levels and prognostic significance. Ann Oncol 12(10): 1423-1432, 2001. PMID: 11762815. DOI: 10.1023/A:1012527006566

41 Rutkowski P, Kaminska J, Kowalska M, Ruka W and Steffen J: Cytokine serum levels in soft tissue sarcoma patients: Correlations with clinico-pathological features and prognosis. Int J Cancer 100(4): 463-471, 2002. PMID: 12115531. DOI: $10.1002 / \mathrm{ijc} .10496$

42 Graeven U, Andre N, Achilles E, Zornig C and Schmiegel W: Serum levels of vascular endothelial growth factor and basic fibroblast growth factor in patients with soft-tissue sarcoma. J Cancer Res Clin Oncol 125: 577-581, 1999. PMID: 10473871. DOI: $10.1002 / \mathrm{ijc} .10496$

43 Yoon SS, Segal NH, Olshen AB, Brennan MF and Singer S: Circulating angiogenic factor levels correlate with extent of disease and risk of recurrence in patients with soft tissue sarcoma. Ann Oncol 15(8): 1261-1266, 2004. PMID: 15277268. DOI: $10.1093 /$ annonc/mdh309

44 Hayes AJ, Mostyn-Jones A, Koban MU, A'Hern R, Burton P and Thomas JM: Serum vascular endothelial growth factor as a tumour marker in soft tissue sarcoma. Br J Sur 291(2): 242-247, 2013. PMID: 14760675 . DOI: 10.1002/bjs.4398

45 Yoon SS, Segal NH, Park PJ, Detwiller KY, Fernando NT, Ryeom SW, Brennan MF and Singer S: Angiogenic profile of soft tissue sarcomas based on analysis of circulating factors and microarray gene expression. J Surg Res 135(2): 282-290, 2006. PMID: 16603191. DOI: 10.1016/j.jss.2006.01.023

46 Schiavetti A, McDowell Heather P, Conti L, Altavista P, Antenucci A, Pizer B and Dominici C: Vascular endothelial growth factor serum levels in children with newly diagnosed rhabdomyosarcoma. Pediatr Blood Cancer 59(4): 627-630, 2012. PMID: 22231858. DOI: $10.1002 /$ pbc. 24072

47 Kuhnen C, Lehnhardt M, Tolnay E, Muehlberger T, Vogt PM and Müller KM: Patterns of expression and secretion of vascular 
endothelial growth factor in malignant soft-tissue tumours. J Cancer Res Clin Oncol 126(4): 219-225, 2000. PMID: 10782895. DOI: $10.1007 / \mathrm{s} 004320050036$

48 Bien E, Balcerska A and Kuchta G: Serum level of soluble interleukin-2 receptor $\alpha$ correlates with the clinical course and activity of Wilms' tumour and soft tissue sarcomas in children. Biomarkers 12(2): 203-213, 2007. PMID: 17536769. DOI: 10.10 80/13547500601066410

49 Bien E, Krawczyk M, Izycka-Swieszewska E, Trzonkowski P, Kazanowska B, Adamkiewicz-Drozynska E and Balcerska A: Deregulated systemic IL-10/IL-12 balance in advanced and poor prognosis paediatric soft tissue sarcomas. Biomarkers 18(3): 204215, 2013. PMID: 23557126. DOI: 10.3109/1354750X.2013. 764351

50 Hagi T, Nakamura T, Iino T, Matsubara T, Asanuma K, Matsumine A and Sudo A: The diagnostic and prognostic value of interleukin6 in patients with soft tissue sarcomas. Sci Rep 7: 9640, 2017 PMID: 28851899. DOI: 10.1038/s41598-017-08781-6

51 Nakamura T, Matsumine A, Ino T, Matsubara T, Asanuma K, Uchida A and Sudo A: Role of high-sensitivity C-reactive protein in the differentiation of benign and malignant soft tissue tumors. Anticancer Res 34(2): 933-936, 2014. PMID: 24511035.

52 Nakamura T, Grimer R, Gaston C, Francis M, Charman J, Graunt P, Uchida A, Sudo A and Jeys L: The value of C-reactive protein and comorbidity in predicting survival of patients with high grade soft tissue sarcoma. Eur J Cancer 49(2): 377-385, 2013. PMID: 23058786. DOI: 10.1016/j.ejca.2012.09.004

53 Nakamura T, Matsumine A, Matsubara T, Asanuma K, Uchida A and Sudo A: The combined use of the neutrophil-lymphocyte ratio and C-reactive protein level as prognostic predictors in adult patients with soft tissue sarcoma. J Surg Oncol 108(7): 481-485, 2013. PMID: 24018883. DOI: 10.1002/jso.23424

54 Nakamura T, Matsumine A, Matsubara T, Asanuma K, Uchida A and Sudo A: Clinical significance of pretreatment serum Creactive protein level in soft tissue sarcoma. Cancer 118(4): 1055-1061, 2012. PMID: 21761398. DOI: 10.1002/cncr.26353

55 Choi ES, Kim HS and Han I: Elevated preoperative systemic inflammatory markers predict poor outcome in localized soft tissue sarcoma. Ann Surg Oncol 21(3): 778-785, 2014. PMID: 24306668. DOI: 10.1245/s10434-013-3418-3

56 Idowu OK, Ding Q, Taktak AFG, Chandrasekar CR and Yin Q: Clinical implication of pretreatment neutrophil to lymphocyte ratio in soft tissue sarcoma. Biomarkers 17(6): 539-544, 2012. PMID: 22793493. DOI: 10.3109/1354750X.2012.699554
57 Cho Hy, Kim K, Kim YB and No JH: Differential diagnosis between uterine sarcoma and leiomyoma using preoperative clinical characteristics. J Obstet Gynaecol Res 42(3): 313-318, 2015. PMID: 26695124. DOI: 10.1111/jog.12915

58 Yang K, Mooney C, Spahlinger G, Schuetze S, Arias-Pulido H, Verschraegen C, Gimotty P and Buckanovich RJ: DR6 as a diagnostic and predictive biomarker in adult sarcoma. PLoS One 7(5): e36525, 2012. PMID: 22567163. DOI: 10.1371/journal. pone. 0036525

59 Tanyildiz HG, Kaygusuz G, Unal E, Tacyildiz N, Dincaslan H and Yavuz G: The prognostic importance of TGF- $\beta$, TGF- $\beta$ receptor, and fascin in childhood solid tumors. Pediatr Hematol Oncol J 34(4): 238-253, 2017. PMID: 29065267. DOI: 10.1080/ 08880018.2017 .1363838

60 Trovik J, Salvesen HB, Cuppens T, Amant F and Staff AC: Growth differentiation factor-15 as biomarker in uterine sarcomas. International Int J Gynecol Cancer 24(2): 252-259, 2014. PMID: 24401984. DOI: 10.1097/IGC.0000000000000037

61 Chen H, Chen Y, Liu H, Que Y, Zhang X and Zheng F: Integrated expression profiles analysis reveals correlations between the IL-33/ST2 axis and CD8(+) T cells, regulatory T cells, and myeloid-derived suppressor cells in soft tissue sarcoma. Front Immunol 9: 1179, 2018. PMID: 29896199. DOI: 10.3389/fimmu.2018.01179

62 Ratti C, Botti L, Cancila V, Galvan S, Torselli I, Garofalo C, Manara MC, Bongiovanni L, Valenti CF, Burocchi A, Parenza M, Cappetti B, Sangaletti S, Tripodo C, Scotlandi K, Colombo MP and Chiodoni C: Trabectedin overrides osteosarcoma differentiative block and reprograms the tumor immune environment enabling effective combination with immune checkpoint inhibitors. Clin Cancer Res 23(17): 5149, 2017. PMID: 28600479. DOI: 10.1158/1078-0432.CCR-16-3186
Received May 27, 2019

Revised June 24, 2019

Accepted June 25, 2019 